\title{
A LITERATURA CONFESSIONAL EXPRESSA NA OBRA DE LYCIA BARROS: UMA ANÁLISE A PARTIR DO LIVRO UMA HERANÇA DE AMOR - O PLANO PERFEITO $^{1}$
}

\section{The confessional literature expressed in the work of Lycia Barros: an analysis from the book An Inheritance of Love - The Perfect Plan}

\author{
Daniela Emilena Santiago Dias de Oliveira*
}

\section{Resenha de:}

BARROS, Lycia. Uma Herança de Amor: O Plano Perfeito. São Paulo: Novo Século, 2015.

\section{Introdução e apresentação do autor}

Conhecer os bens simbólicos religiosos que estão presentes em nossa sociedade nos dá a saber de uma importante expressão cultural do povo brasileiro. A aproximação dos romances confessionais, como o que resenhamos nesse texto, nos apresenta como o romance vem sendo retratado por autores ligados às religiões cristãs. Portanto, nesse texto, partimos do entendimento que o romance confessional é um importante dispositivo da difusão de uma cultura peculiar e específica e que também pode ser lido como um meio para a uniformização de práticas sociais. Para isso, usamos como exemplo, uma obra de Lycia Barros.

Lycia Barros ${ }^{2}$ é graduada em Letras pela UFRJ e autora de vários romances protestantes. Por romance protestante designamos livros que apresentam uma narrativa em prosa, com uma história longa, e que, no caso, apresenta um viés religioso. O livro Uma Herança de Amor - O Plano Perfeito, publicado em 2015, faz parte de uma trilogia composta por dois outros livros: Uma Herança de Amor - Quando o fim pode ser o começo e Uma Herança de Amor - Armadilhas do Destino, publicados em 2013 e 2014, respectivamente. Essa trilogia, publicada pela Editora Novo Século, integra um rol importante de romances da autora, porém, destina-se ao público adulto e juvenil. Apesar de não termos dados específicos sobre a tiragem dos livros até o presente momento, vemos que os exemplares que adquirimos estão na terceira edição, ou seja, é algo que traz lucro à editora, ou não haveria outras tiragens. Além disso, o livro é comercializado pelo grupo editorial Novo Século, pelo site da autora e por páginas como, Saraiva, Submarino e também pelo Amazon, indicando que trata-se de um livro que não é comercializado somente nos espaços evangélicos.

1 Enviado em: 24.01.2019. Aceito em: 22.04.2020.

* Doutoranda em História (UNESP). Mestrado e História e Psicologia (UNESP). Graduada em Serviço Social. Docente dos Cursos de Pedagogia e Psicologia da UNIP (SP). E-mail: santiago.dani@yahoo.com.br

2 Disponível em: http://lyciabarros.com.br. Acesso em 22 de Jan. de 2019.

Protestantismo em Revista | São Leopoldo | v. 45, n. 02 | p. 177-180| Jul./dez. 2019

Disponível em: <http://periodicos.est.edu.br/index.php/nepp> 


\section{Uma Herança de Amor - O Plano Perfeito: apresentando a obra}

Como indicamos, o livro que apresentamos faz parte de uma trilogia. Integram a trilogia os livros: Uma Herança de Amor - Quando o fim pode ser o começo ${ }^{3}$, Uma Herança de Amor Armadilhas do Destino ${ }^{4}$ e Uma Herança de Amor - O Plano Perfeito ${ }^{5}$. O primeiro livro, Uma Herança de Amor - Quando o fim pode ser o começo, conta a história de Amanda, narrando o seu relacionamento com Adam. Já o segundo livro, Uma Herança de Amor - Armadilhas do Destino, passa a narrar a história de Rafael e Alexia e o último livro, Uma Herança de Amor - O Plano Perfeito, apresenta o relacionamento de Ivy e Leonardo.

Todas as histórias, no entanto, estão centradas na família de Janine e Paulo. Janine é casada com Paulo, com quem tem a filha Ivy. Paulo possui filhos gêmeos do primeiro relacionamento, Adam e Rafael. Amanda, por sua vez, é filha do primeiro relacionamento de Janine com Marcelo. A história do primeiro livro parte da situação de Amanda. Amanda fora criada pela avó no Rio de Janeiro após a morte do pai. O livro conta que Marcelo disputou a guarda de Amanda com Janine, que era alcoolista, e saiu vitorioso. No primeiro dia de Amanda com o pai e a nova namorada, Debora, Janine tenta reaver a filha e a sequestra. No confronto entre Janine e Marcelo, o pai de Amanda atira na ex esposa e acaba preso. Por conta disso, Marcelo é preso e se suicida. Marcelo e Débora tinham um filho, Leonardo. E Leonardo que reaparece no último livro e passa a se relacionar com Ivy.

Assim, o último livro Uma Herança de Amor - O Plano Perfeito, é centrado na história de Ivy e Leonardo. Ivy aparece no primeiro livro como uma menina já evangélica, mas nesse livro, com então dezoito anos, cursa faculdade em Ouro Preto. Mesmo na universidade, mantém os princípios de sua fé. Quando Ivy vai para a casa de férias da Universidade em São Lourenço conhece Leonardo. Leonardo é apresentado como surfista, rapaz de muito dinheiro e por quem Ivy se apaixona. Leonardo, no entanto, era filho de Débora, que foi namorada de Marcelo, pai de Amanda e voltou a São Lourenço apenas para se vingar de Janine. O livro narra que Débora, após o suicídio de Marcelo, desenvolveu depressão, usando muitos medicamentos e se afastando do filho, Leonardo.

No entanto, Ivy e Leonardo se envolvem e a família toda dela é contrária ao relacionamento do casal. Ela abandona a família e segue com ele para Santa Catarina. O casal fica noivo e decide se casar. Até o casamento Ivy fica em uma pousada e o casal não tem relacionamento sexual. Após o casamento, ambos passam a morar juntos e na noite de núpcias do casal, ele a estupra ${ }^{6}$.

3 BARROS, Lycia. Uma Herança de Amor: quando o fim pode ser o começo. São Paulo: Novo Século, 2013.

4 BARROS, Lycia. Uma Herança de Amor: Armadilhas do Destino. São Paulo: Novo Século, 2014.

5 BARROS, Lycia. Uma Herança de Amor: O Plano Perfeito. São Paulo: Novo Século, 2015.

6 No entanto, Ivy ofegou de susto quando Leonardo arrancou a sua calcinha, arrebentando-a, e, impaciente, empurrou-a com brutalidade para a cama. Depois, lançou-se sobre ela. A urgência dele era inegável. Mas, embora Ivy estivesse com a mesma euforia, gostaria de fazer aquilo tudo com calma. Apreciar cada momento. Mas Leonardo nem deu tempo para ela hesitar. Arrancou a própria calça rapidamente e, afastando seus joelhos, arremeteu contra ela. Ivy sentiu muita dor e um gemido alto escapou dos seus lábios. Momentaneamente, ele ficou paralisado, e ela pensou notar um breve olhar mortificado em seus olhos... Mas, em seguida, Leonardo continuou. Implacável, bruto, inegavelmente indiferente à sua dor. Mesmo a mulher mais insensível do mundo perceberia como ele havia mudado. Não olhava para ela. Seu corpo estava ali, mas não podia se dizer o mesmo da sua mente. Não houve muitas carícias entre eles, somente o domínio de Leo. Ivy somente fechou os olhos e mordeu os lábios enquanto ele continuava, imaginando que a primeira vez devesse ser assim mesmo. Talvez, ela pensou, tentando se convencer, o desejo que ele estava sentido por ela fosse tão forte que o impedisse de ser mais carinhoso. Assim que acabou, sem dizer uma única palavra, Leonardo chutou o lençol e se levantou para ir ao banheiro, trancando-o. Para assimilar o choque, Ivy sentou-se vagarosamente na cama, ainda dolorida. Era como se tivesse sido sacudida por uma tempestade e de repente tudo estivesse girando. O que fora aquilo? [...]. Sem que Ivy pudesse impedir, sentiu as lágrimas de decepção

Protestantismo em Revista | São Leopoldo | v. 45, n. 02 | p. 177-180| Jul./dez. 2019

Disponível em: <http://periodicos.est.edu.br/index.php/nepp> 
Depois disso, muitas brigas e desentendimentos acontecem entre o casal, porém, eles começam a ter uma vida sexual sem abuso. No entanto, em nenhum outro trecho do livro é feita menção ao abuso sofrido por Ivy. A agressividade da relação sexual vem acompanhada com relatos de abandono, uma vez que Leonardo passa a negligenciar Ivy, ficando dias sem falar com a esposa. Ivy estava em um local que não conhecia ninguém, sem contato algum com sua família, sem seus amigos e a única pessoa que conhecia era o esposo, que permanecia dias sem dirigir uma palavra a ela. Ivy decide então que iria trabalhar, mas Leonardo veta sua inserção laboral. A história chega ao ponto em que Ivy descobre que Leonardo era filho de Débora e consegue ainda saber que o plano dele era agredi-la, para assim fazer sua mãe, Janine, sofrer.

Quando ela descobre os objetivos de Leonardo, o deixa e volta a morar com os pais em São Lourenço, já grávida. Ela permanece a gravidez toda sem o apoio de Leonardo, até que próximo ao bebê nascer, ele a procura em São Lourenço, destacando que passou por um processo de conversão. Aliás, Leonardo vai até São Lourenço acompanhado do antigo pastor de Ivy em Santa Catarina. Nesse momento, tudo que foi vivido entre o casal é perdoado, e agora Leonardo é aceito pela família, além de Ivy. Leonardo permanece em São Lourenço e o casal sobrevive dos imóveis que ele possui e que herdara da mãe. Ivy abandonara a faculdade quando decide ir para Florianópolis com Leonardo e depois, com a chegada do segundo filho do casal, decide esperar um tempo para voltar a estudar. Também nesse caso, é Leonardo que impõe isso à mulher.

Ao final do livro é apresentada uma situação em que todos os membros da família estão em um churrasco, na casa de Janine, mãe de Ivy. A autora fecha o texto destacando que momentos como aquele, em que todos os membros da família estão reunidos em família só são possíveis porque na convivência entre eles houve amor e perdão. Assim, parafraseando com o título do livro, a autora indica que somente uma vida próxima à Deus daria ao ser humano momentos de felicidade. Para a autora, a imagem dos filhos e netos reunidos na casa da mãe e do pai era o maior retrato de felicidade, portanto, essa seria a maior herança de amor que alguém poderia receber.

\section{Considerações Finais}

Gostaríamos de indicar que inserimos trechos longos do livro na resenha pelo fato de que consideramos que são vitais a compreensão da obra. No entanto, pela natureza desta resenha, obviamente muitos trechos foram suprimidos. No entanto, consideramos que o cerne da estória foi compreendido e apesar de não termos conhecimento profundo para uma análise crítica do livro, ousamos arriscar algumas colocações.

Por exemplo, a autora aposta na fórmula: protagonista bom, que passa por momentos de sofrimento, porém, ao final, consegue superar todas as vicissitudes e ser feliz. Nessa obra, o antagonista, expresso inicialmente em Leonardo também começa como vilão, mas vai sendo transformado em uma pessoa boa no decorrer da obra uma vez que a autora começa enfatizar a sua vida sofrida, sem pai e com uma mãe ausente. No entanto, diferente dos romances convencionais essa obra apresenta como alternativa para a superação dos indivíduos a sua vinculação à fé cristã. Assim, se em outros romances as qualidades e os defeitos dos indivíduos estão relacionados a sua conduta e a seu sucesso e, também, o seu fracasso, nesses romances, o que torna as pessoas boas ou más é a sua observação da Bíblia, a vinculação a uma fé. Tanto é que Ivy sofreu quando se afastou de sua fé e voltou a ser feliz quando a reencontrou.

virem aos olhos, indescritivelmente magoada. Seus sonhos e esperanças sobre sua lua de mel haviam acabado de virar pó. Não era possível que Leonardo tivesse feito aquilo com ela. Não daquele jeito (BARROS, 2015, p. 160-161).

Protestantismo em Revista | São Leopoldo | v. 45, n. 02 | p. 177-180| Jul./dez. 2019

Disponível em: <http://periodicos.est.edu.br/index.php/nepp> 
Mas, porque esses romances são tão lidos, quando, usam de fórmulas já convencionais do espaço literário? A nosso ver, são lidos porque todos os seres humanos já passaram por essas situações: o primeiro amor, as tristezas e decepções, e outras situações específicas. E, com certeza, são consumidos por pessoas que também partilham dos ideais ali difundidos. Caso contrário, não haveria o encontro entre a estória e o leitor, e, com certeza os itens em questão não seriam comercializados.

Dessa maneira, o fato de haver várias edições do livro e, também, em virtude de o mesmo ser comercializado em sites além dos confessionais, nos indica que esses romances são a expressão de um segmento peculiar. Assim, os livros só podem ser vendidos ao passo que há vinculação entre o que é escrito e o que é consumido, comercializado. Conhecê-los nos dá a saber como um grupo peculiar, os cristãos, compreendem a realidade, ou seja, como idealizam os relacionamentos, a vida cotidiana e outros aspectos afins. Assim, conhecer esse tipo de impresso é também conhecer a cultura de um dado extrato de nossa sociedade.

No entanto, o que chama a nossa atenção é a forma com que os leitores poderão se apropriar dessa obra, em especial. Seria possível as pessoas estabelecerem uma analogia com a personagem de Ivy e supor então que como ela também poderemos sofrer tudo que ela sofreu e sobreviver, e, ser feliz? Seria possível que as mulheres que porventura leiam essa obra se espelhem no "exemplo" de Ivy e aceitem o estupro, uma relação doentia e possessiva? E mais, seria possível que os leitores acreditando no poder da fé perdoassem tudo que lhes infringisse, lhes humilhasse esperando que Deus os justificasse? Isso é algo a ser pensado, pois, em que medida o impresso viabiliza a apropriação de conceitos dos seres humanos, fortalecendo neles práticas sociais e até que ponto dadas condutas não fortalecem o papel de subalternidade feminino e sustentam agressões como algo que deve ser aceito na esperança de um futuro melhor? Isso é algo a se pensar.

\section{Referências}

BARROS, Lycia. Uma Herança de Amor: armadilhas do Destino. São Paulo: Novo Século, 2014.

BARROS, Lycia. Uma Herança de Amor: o Plano Perfeito. São Paulo: Novo Século, 2015.

BARROS, Lycia. Uma Herança de Amor: quando o fim pode ser o começo. São Paulo: Novo Século, 2013. 